\title{
Introduction
}

\section{Najma Al Zidjaly* \\ Society in digital contexts: New modes of identity and community construction}

https://doi.org/10.1515/multi-2018-0042

Keywords: sociolinguistics, digital discourse, intercultural communication, social media, local and global, identity and community construction

\section{What this special issue is about}

This thematic volume of sociolinguistic research focuses on identity and community construction at the interface of the local and the global, examining these phenomena using varied research methods and through the lenses of diverse analytical and theoretical perspectives. The papers highlight the intricacies inherent in identity and community construction in digitized contexts through the exploration of linguistic and semiotic resources, languages, and understudied cultural contexts as varied as the use of emojis to defy bias against female gamers online, initiation of repair on expert-authored blogs on weight loss, negotiation of language ideologies on Ukrainian Twitter, and the construction of political dissent on Arabic Syrian Facebook. The volume satisfies four additional aims: It (a) considers the local and global to be interconnected and mutually influencing, (b) conceptualizes and examines language as one of numerous semiotic resources, (c) explores online interaction as linked to interaction offline, and (d) acknowledges human agency and creativity. Collectively, the studies add to the ongoing quest for new ways to use and investigate language in society by examining the ways society manifests itself creatively in various languages and across globalized mediums. ${ }^{1}$

1 I am indebted to Jan Blommaert for coming up with the original special issue title "Society in Language," as opposed to the traditional ideology "Language in Society." The former stresses the need to upend sociolinguistic theory as we know and practice it. I later changed the title to

*Corresponding author: Najma Al Zidjaly, The Department of English Language and Literature, College of Arts \& Social Sciences, Sultan Qaboos University, Muscat, Oman,

E-mail: najmaz@gmail.com 
The volume also emphasizes the need to continue to develop sociolinguistic theory and methodology in the context of contemporary communication practices. In doing so, the studies expand current discussions on the place of sociolinguistics and social media research in an increasingly globalized and digitized world. The remainder of this introduction contextualizes the studies by providing a synopsis of key factors in the study of the sociolinguistics of social media.

\section{New directions in sociolinguistics}

Calls for new directions in sociolinguistics abound, precipitated by rapid globalization (Bell 2016; Blommaert 2003, Blommaert 2010, Blommaert 2011, Blommaert 2016, Blommaert 2017a, and Blommaert 2018a; Coupland 2003, Coupland 2016; Park and Lo 2012; Rampton 1996, Rampton 1998) and technological revolutionparticularly the spread of social media use across contexts and cultures (Androutsopoulos 2006, Androutsopoulos 2013; Barton and Lee 2013; Bou-Franch and Blitvich 2018; Georgakopoulou 2006; Georgakopoulou and Spilioti 2016; Lee 2017; Pennycook 2018). The sociolinguistics of globalization has, in particular, highlighted global identity construction in the context of multilingualism (e.g. Heller 2007; Park and Lo 2012) and language ideology, chiefly English as a global phenomenon (e.g. Rubdy and Alsagoff 2014). Despite the surge of research on social media from a discursive perspective (e.g. Herring 2004, Herring 2013a, and Herring 2013b), sociolinguistic examinations of identity construction conducted online apropos globalization have been notably absent, as pointed out by Androutsopoulos (2013) and Thurlow and Mroczek (2011). This is in spite the fact that language is simultaneously both a local and a global construct (Al Zidjaly 2006; Erickson 2004). ${ }^{2}$ Notwithstanding the paucity of linguistic research on global and local identity construction online, the consensus among sociolinguists is that the digital turn has created emergent identities and practices that merit linguistic investigation using new research and methodology toolkits. ${ }^{3}$

\footnotetext{
"Society in Digital Contexts" to account for the multimodality of human interaction, aptly exemplified in the special issue.

2 Erickson (2004) explains that talk/interaction is both local and global because talk itself takes place in real time among real social actors to satisfy immediate goals. At the same time, all interactions are also global, as they are always occasioned by processes that occur outside the immediate context.

3 I take the position that the lines between online and offline are porous, as argued by Barton and Lee (2013), Blommaert (2017a) and Locher et al. (2015), as people are "always on" and their
} 
"New directions" for sociolinguistics is not an uncommon theme. The field of sociolinguistics has been built upon revisiting and readapting sociolinguistic concepts to match social reality. From the onset of the field, and through building on social and literary theorists (e.g. Bakhtin 1981; Goffman 1971), key sociolinguists (e.g. Hymes 1996; Ochs 1996; Silverstein 1976) had to upend traditional ideas about language, communication, and social groups to create a theory of language in society (Blommaert and Rampton 2011) wherein established concepts about identity and social integration are revisited. (Examples of such ongoing activity of sociolinguistics include: Barton and Lee 2013; Bell 1984; Blommaert 2003, Blommaert 2005; Coupland 1998, Coupland 2013, and Coupland 2016; Danesi 2015; Erickson 2004; Georgakopoulou 2007; Park and Lo 2012; Pennycook 2007, Pennycook 2018; Piller 2011, Piller 2016; Rampton 1996; Scollon 2001). ${ }^{4}$ The need to keep 'the theory' in dialogue with ever shifting social realities has intensified with the onset of globalization and technological advancement. ${ }^{5}$ An additional factor that has necessitated the reconceptualization of sociolinguistic concepts and methodologies has to do with the creativity and agency of social actors across the globe (especially in non-Western contexts) who have used and adapted social media platforms for their own strategic social, personal, and cultural purposes, thus, not only creating novel forms of interaction and integration but also new means to form communities. ${ }^{6}$ Social agency, however, has largely remained backgrounded as a key factor in redesigning a new theory of sociolinguistics capable of keeping alive the complexities inherent in communication-digital or otherwise (see Al Zidjaly 2014a, Al Zidjaly 2015, and Al Zidjaly 2019a for a discussion on social agency, activism, and linguistic research).

Blommaert (2016), a key leader in the new directions of sociolinguistics, divides recent movements towards a new theory of sociolinguistics into two

daily interactions are inextricably intertwined with new communication technologies (Baron 2008).

4 Other examples of sociolinguists building theory include Gumperz's (1982) theory of conversational inference, Tannen's (2001) work on the ambiguity and polysemy of linguistic strategies, Bucholtz and Hall's (2005) sociocultural linguistic approach to identity, Locher and Watts' (2005) theorization of face and politeness as relational work, Du Bois' (2007) stance triangle, and Al Zidjaly's (2009, 2015) theorizing of agency (I am indebted to Cynthia Gordon for these specific examples).

5 Revisiting theories as a result of globalization and technological advances has been an activity in other fields as well (including disability studies), not just sociolinguistics (see Watson and Roulstone 2014).

6 See, for example, the use of social media in the Arab world (Al Zidjaly 2012, Al Zidjaly 2014a, Al Zidjaly 2014b, and Al Zidjaly 2017; Al Zidjaly and Gordon 2012). 
periods. The first period, which Blommaert declares as largely accomplished, concerns a move from relative stability to mobility. In this move, superdiversity as an outcome of mobility (Blommaert and Rampton 2011; De Fina et al. 2017; Vertovec 2007) has succeeded in reconceptualizing key sociolinguistic concepts (e.g. multilingualism) by painting a more complex and dynamic view of social reality (e.g. the shift from code-switching to translanguaging). A second move, still in its infancy, concerns a shift from mobility to complexity (Blommaert 2016; Blommaert and De Fina 2015; Pennycook 2018). This shift aims to capture the intricacies of social organization and allows scholars to better theorize the murky and largely challenging concept of context (Cicourel 1964; Duranti and Goodwin 1992; Scollon 2001). The move to complexity goes one step further than the earlier move to mobility by "reimagining the sociolinguistic phenomena and processes we intend to study" through acquiring a new "set of images and metaphors that appear to offer more and better analytical opportunities because they correspond better to the phenomena and processes we observe" (Blommaert 2016: 248-249). In short, a new research toolkit to capture identity in interaction is needed, as "the traditional vocabulary of linguistic analysis is no longer sufficient” (Blommaert and Rampton 2011: 9). ${ }^{7}$

What is entailed in such research is a foregrounding of the inherent complexity in social (inter)actions through detailed analyses of case studies from across cultures, languages, and mediums. Such studies may include ethnography (with a focus on action Blommaert 2018e, this volume), as suggested by researchers of the sociolinguistics of globalization (e.g. Blommaert 2018b; Blommaert and Rampton 2011; Rampton 2006); multi-methods, as suggested by scholars of new media sociolinguistics ${ }^{8}$ (e.g. Androutsopoulos 2008; KhosraviNik 2016); integrative research frameworks (e.g. mediated discourse analysis Scollon 2001 and nexus analysis Scollon and Scollon 2004), as suggested by discourse analysists (e.g. Al Zidjaly 2019a; Georgakopoulou 2006). ${ }^{9}$ In this reimagination, the researcher's task is to highlight the inherent multimodality of human interaction (Norris 2011; Scollon and LeVine 2004; van Leeuwen 2004) and complexity through unfolding "the complex and multifiliar features and their various different origins that are contained in synchronized moments

7 According to Pennycook (2018), complexity entails the question of how much inclusion is too much. He thus raises the question of the cost of including everything in our theories and research projects.

8 In this volume I use computer-mediated discourse analysis (Herring 2004) interchangeably with internet linguistic research (Crystal 2011; Herring and Androutsopoulos 2018) and new media sociolinguistics (Thurlow and Mroczek 2011) to refer to research that analyzes digital discourse. 9 For more new methods and approaches to digital discourse, see Blommaert (2018a, 2018b, 2018c, 2018d, 2018e), Bou-Franch and Blitvich (2018), Gee (2014), and Pennycook (2018). 
of understanding" (Blommaert 2016: 252). This is a vision that extends the contribution of many sociolinguistic scholars who have addressed the issue of complexity through their work (e.g. Erickson 2004; Pennycook 2007, Pennycook 2018; Piller 2016; Scollon and Scollon 2004; Tannen 2001) by providing a critical, qualitative, and bottom-up approach that contributes to social theory in general (not just sociolinguistics) with the aim to upend the existing "authoritative discourses" (Bakhtin 1981) of sociolinguistics and transforming them into "internally persuasive discourses" that are continuously negotiated.

\section{Social media: Complex identity construction sites}

No media highlight the complexity of contemporary social and interactive landscapes better than social media, as they illuminate ongoing identity construction across contexts and scenes. Social media not only provide sites where the local and the global encounter one another, but they also offer contexts wherein semiotic resources co-exist-often, but not always, easily accessible and used in the creation of communication characterized by seemingly endless forms and functions. To understand the relationship between social media and identity construction in globalized contexts, I provide below a synopsis of three key concepts: globalization, identity, and community.

\subsection{Globalization}

Drawing upon Appadurai (1996) and Castells (1996), Blommaert (2010: 13) defines globalization as referring to "the intensified flows of capital, goods, people, images and discourses around the globe, driven by technological innovations mainly in the field of media and information and communication technology, and resulting in new patterns of global activity, community organization and culture." The concept of globalization is non-linear and multifaceted (Coupland 2013), transforming the world into a complex place. As a result, Barton and Lee (2013) argue that when talking about language, the relation between the local and the global is best understood in terms of glocalization, defined by Koutsogiannis and Mitsiopoulou (2007: 143) as the "dynamic negotiation between the global and the local, with the local appropriating elements of the global that it finds useful, at the same time employing strategies to retain its identity." To date, the focus in sociolinguistics has been on research that either globalizes the local (i.e. English 
as a global language e.g. Rubdy and Alsagoff 2014) or foregrounds local appropriation of the global (e.g. localizing YouTube among Germans Androutsopoulos 2013 or localizing American hip hop music Pennycook 2007). Globalization, however, is a two-way medium (Barton and Hamilton 2005). Additionally, while the relationship between language and global identity construction has been studied extensively to date (see Barton and Lee 2013 for an overview), its examination in relation to new media has been largely backgrounded, as noted by Androutsopoulos (2013). This is where this special issue comes in.

What is needed are more case studies (and in due time more interdisciplinary research) that transcend binary theorization (i.e. globalising the local or localizing the global) by examining what people actually do at the interface of the local and the global in terms of the multimodal strategies used and for what ends. ${ }^{10}$ The interface of the local and the global has been referred to as translocality, a concept similar to the theorization of glocalization that has been argued to be key in examining how the local and global intersect specifically in multi-semiotic digital environments (Kytölä 2016). ${ }^{11}$

A recent example of research I have conducted in this spirit considers how citizens in Oman use emojis on WhatsApp to mitigate face threatening acts of dissidence in their Islamic Arabic cultural context, which highlights placidity and uniformity. Citizens simultaneously localize a global semiotic resource and globalize a local issue (i.e. government corruption), thereby constructing a new 'hybrid' identity: A placid Omani dissident that the Omani government is heeded to notice (see Al Zidjaly 2017). An additional example involves my documenting of complex identity work by an online community of anonymous former or "ex-" Muslims on Arabic Twitter (note that for political and religious reasons the identity of ex-Muslims cannot for the time being exist outside of social media). ${ }^{12}$ Through creating tweets that draw upon various discourses, actions

10 van Leeuwen and Suleiman (2013) have made a similar argument.

11 The interface of the local and the global also points to Inda and Rosaldo's (2008: 11-12) idea that "globalization implies a heightened entanglement of the global and local such that, while everyone might continue to live local lives, their phenomenal worlds have to some extent become global as distant events come to have an impact on local spaces, and local developments come to have global repercussions."

12 I refer to the actions I captured on Arabic Twitter as involving complex identity work because I found it difficult to insightfully interpret and analyze the tweets shared on this community of ex-Muslims and capture their immediate and yet to be realized effects on identity without drawing on a plethora of methodological frameworks, pushing theorizing on social identities into new, multimodal territories, and taking into consideration smaller and larger scale discourses and practices about Islam, Muslim countries, and globalization. Of particular 
and linguistic and multimodal strategies, I demonstrate how a group of Arabs with no offline legitimacy manages to not only create an active 'light' community online but also to contribute to convincing hundreds of other Muslims (by their own admission on \#whyIleftIslam) to renounce Islam, an act punishable by death in Islamic countries, and an act destined to change the very fabric of Arab societies ingrained in religion (see Al Zidjaly 2019a, Al Zidjaly 2019b for details). Therefore, Coupland $(2013,2016)$ rightly argues that social analysis needs to be framed in relation to an increasingly globalized society. I add to this the proposal (following Blommaert 2016, Blommaert 2017a, and Blommaert 2018a) that linguistic research needs to explore identity construction at the nexus of the local and the global, regardless of how fleeting, malleable, and seemingly inconsequential such actions and identities might seem (i.e. regardless of their lightness).

\subsection{Identity}

Like globalization, identity is also demanding and multi-layered (Coupland 2016), best examined, sociolinguists have demonstrated, within a social constructivist approach (e.g. Bucholtz and Hall 2005; De Fina et al. 2006). Thus, Lee (2017: 55) notes that identities are "always open to reappropriation, recontextualization, and transformation" and that they require constant revisiting in light of technological advances and the resulting and interconnected social dynamics-such as in the present era of ubiquitous social media use across the globe. As globalization intensifies identity construction processes, Blommaert (2005: 207) argues that identity is best conceived as "particular forms of semiotic potential, organized in a repertoire." Analytically, conceiving of identity in terms of participants' access to a range of mobile resources that potentially could be drawn upon to enact (or perform, per Goffman 1959) certain kinds of identities (Rampton 1999, Rampton 2001) highlights human agency, creativity, and unpredictability. In line with the second move of sociolinguistics from mobility to complexity, Blommaert (2015a, 2015b) additionally suggests conceiving of identities as chronotopes

interest were those discourses occurring in the Arabian Gulf, the cradle of Islam. That is, to create (and capture) cultural revolution, the members of the ex-Muslim community, their followers, and I as a researcher had to negotiate all types of higher and lower level actions and discourses (Lemke 2000; Norris 2011) to incite (and sociolinguistically capture the impetus of) cultural revolution (see Al Zidjaly 2019a, Al Zidjaly 2019b for details). 
(Blommaert and De Fina 2015) especially in digitized contexts. ${ }^{13}$ The Bakhtinian idea of chronotope (literally meaning time/place Bakhtin 1981) invokes orders of indexicality framed in terms of time and place (Blommaert 2005; Blommaert and De Fina 2015). This complex view of identity construction, constrained by access to resource mobility and framed chronotopically, eradicates simplistic and dichotomist views of identity construction (as local/global) and foregrounds a view of identity as complex interactive negotiations that merit various levels of contextualization..$^{14}$ It also opens up a space to examine light identities-ludic, loosely-formed, ephemeral formations enabled by social media that, according to Blommaert (2016, 2017b, 2018a), are key to social organization (in contrast to the oft sociolinguistically foregrounded thick identities [e.g. nationality, race]).

That identities are complex is not new to sociolinguistics (see Bucholtz and Hall 2005; Piller 2016; Schiffrin 2000); but what is new is the need to keep the theory and methodology up with the heightened degree of complexity and diversity exemplified in identity construction in increasingly digitized and translocalized contexts.

\subsection{Community}

A major challenge to sociolinguistics, according to Coupland (2016: 32), is the concept of 'community,' which Herring (2004) calls 'inherently abstract,' originally theorized as "local, face-to-face mutual engagement [in speech communities, in social networks, or in communities of practices]." Efforts, however, have been established to properly retheorize the traditional concept of community within sociolinguistic research in light of globalization (see e.g. Coupland 2010; Rampton 1998, Rampton 1999, and Rampton 2006). Rheingold (1993) coined the term 'virtual community' to conceptualize digitally mediated affiliations, in particular. From its inception, Herring (2004) argues, the term attracted both attention (as a tool to understand how the Internet facilitates relationship creation e.g. Zappavigna 2011, Zappavigna 2012) and philosophical and methodological criticism. Early research on online discourse highlights the properties of virtual communities (i.e. what makes online different than offline communities Herring

13 Norris (2011: 30) uses the term "identity elements" to capture the chronotropic aspect of identity. In her words, "identity is embedded and (co)produced in the social-time-place of a particular social actor together with other social actors, together with and within the historical time, together with cultural tools, and together with and within the environment."

14 For more on the complexity of identity construction, see Piller (2016) and Seargeant and Tagg (2014). 
1999). Herring and Androutsopoulos (2018) argue that as the lines between online and offline blurred, researchers from the second wave of linguistic Internet studies moved from examining discourse on virtual communities as standalone to examining how social actors mediate online/offline social realities (e.g. Jones 2009). Recent research has further moved from examining self-presentations and member profiles online (Page 2010) to investigating the micro-discursive features and interactive patterns used by participants to form communities (e.g. Baym 1995, Baym 2015; Gordon 2015; Graham 2007, Graham 2018; Seargeant and Tagg 2014; Vasquez 2014).

These examinations have highlighted the inadequacy of the term 'virtual community' in capturing the kind of simultaneously fleeting and unbounded, yet real and somehow identifiable communities created based on choice, access, shared interest, and/or goals, with percolating effects to offline realities (what is referred to in the papers presented in this collection as light identities following Blommaert 2017b, Blommaert 2018a). As a result, a plethora of new terms have been proposed with varying degrees of success, such as: affinity groups (Gee 2005; Gee and Hayes 2011), imagined solidarity (Kramsche and Boner 2013), ambient affiliation (Zappavigna 2011, Zappavigna 2012), communities of knowledge or chronotopes "in which specific identity resources can be formed, learned and policed” (Blommaert 2017b: 123), and light communities (Blommaert 2017b, Blommaert 2018a; Blommaert and Varis 2015). Collectively, research indicates that the numerous factors characterising digital communication-including absence of physical space and ease of anonymity, the agency of social actors, the abundance of multimodal resources with various degrees of accessibility, and the blurring of online/offline social realities-give way to a surplus of new forms of social integration, the kind sociolinguists never had to deal with before, resulting in new challenges for language in society research that merit immediate and adequate identification, examination, and sociolinguistic theorization. ${ }^{15}$

\section{Society in language: An overview of studies}

Sociolinguistics as we know it is metamorphosing in favor of critical constructivism, complexity, fluidity, transience, and multiple forms of semiosis (Bell 2016;

15 These new kinds of uses and challenges have led some scholars (e.g. Rymes and Leone 2014) to create the subfield of citizen sociolinguistics. 
Blommaert 2016; Pennycook 2018). This shift requires a sociolinguistic reimagination built upon bottom-up critical and qualitative research that engages with an updated agenda of new media sociolinguistic research that highlights the integration of research methods (e.g. multimodality, ethnography and discourse analysis), ethics, and ideologies. The shift further necessitates examining interaction in the context of 'light' groups, so-called ludic communities of knowledge, which have traditionally been dismissed within mainstream empirical and theoretical sociological literature. In contrast, this issue deliberately considers light groups and participants' identity construction behavior, as, per Blommaert, they inform our understanding of contemporary social reality and, I argue, current debates in new media sociolinguistics.

\subsection{The question of revisiting linguistic concepts}

Cynthia Gordon's sociolinguistic take on "Other-Initiated Repair and Community-Building in Health and Weight loss Blogs" highlights the need to test and, in time, retheorize established linguistic strategies in light of new forms of interaction. This necessity was emphasized by Blommaert (2018c) in his argument for the validity of retheorizing context as chronotopes. Whereas context seems ever-problematic, repair, a communicative sub-process key to the organization of human interaction (Schegloff et al. 1977), has been generally conceptualized as formulaic, interactive, and limited in function (i.e. mainly connection or disconnection). ${ }^{16}$ In this one of very few examinations of repair on social media (and the first in blogs), Gordon presents a deeper, more complex look into the mechanisms of other-initiated repair in anonymous user comments, theorizing repair as a light practice which highlights cultural expectations while creating fleeting moments of community-building. The analysis also identifies a new type of repair-that of images-which cements the postulation by Schegloff (2007) that any aspect of turn can be repaired and demonstrates the multimodality of repair made visible by social media users. The detailed analysis of the workings of repair maintains the need to transcend comparative approaches (e.g. online verses offline differences in use) to contextual approaches that consider the nature and goal of communities in examining semiotic resources.

16 Few exceptions exist, including Meredith and Stokoe (2014). 


\subsection{The question of political activism and ethics}

Francesco Sinatora's examination of "Chronotopes, Entextualization and Syrian Political Activism on Facebook" engages in two firsts: It is the first sociolinguistic documentation of Syrian Arabic dissident identity (on Facebook) and it is one of the first qualitative, critical, mixed methods studies that in my opinion complicates the debate on the relationship between social media and activism (whether social media lead to social change Al Zidjaly 2014 a or slacktivism Morozov 2011). This debate gripped both academia and the public on Twitter in 2018 preceding the mid-term American elections. The Syrian Arab Spring example demonstrates the chronotopic constraints of such connections by larger discourses of politics and economics (Al Zidjaly 2018). As a documentation of political dissent in a region that lacks freedom of expression, the paper, most importantly, touches upon the question of academic ethics and ideologies, a main objective of the third wave of new media sociolinguistics (Georgakopoulou and Spilioti 2016). As researchers of Arabic political activism, Francesco and I have had many a great discussion about the dangers of using the real names of his research participants. ${ }^{17}$ This second study is thus unique in its examination of chronotopes in the context of political activism, contribution to sociolinguistics, and the raising of concerns (albeit indirectly) that all academics, especially those involved in activism research, must heed.

\subsection{The question of user comments and grassroots movements}

Alla Tovares' account of "Negotiating “Thick" Identities Through "Light" Practices: YouTube Metalinguistic Comments About Language in Ukraine" demonstrates the shift in new media sociolinguistic research from examining self-presentations online to examining users' metalinguistic comments, which the author aptly theorizes as light practices that can create digital inclusion or exclusion from particular language ideologies and social groups. ${ }^{18}$ This study also is one of the few extant sociolinguistic examinations of balancing

17 See Al Zidjaly (2019a) to learn more about the dangers of conducting activism research in religiously and politically volatile Arabic contexts. It should be noted that Alla Tovares and Cynthia Gordon were also part of the discussion on the ethicality of using names and usernames in our academic research.

18 Refer to Al Zidjaly (2010) and Seargeant and Tagg (2014) to find more about this shift in sociolinguistics from the examination of self presentations to user comments. 
translocality and audience design (i.e. harmonizing between local attitudes and global themes in an understudied online space). It additionally is an empowering documentation (akin to Francesco Sinatora's study on Syrian activism), as the study contributes to debates on social media and inclusion by presenting a bottom-up critical example of how inclusion/exclusion is realized through Bakhtin's (1981) "heteroglossia with awareness.” This study further is a distinctive examination of surzhyk, a complex nonstandard Russian-Ukrainian mixed variety that reflects the intricacies of language ideologies among Ukrainians. Through "engaging with policing, reifying, and contesting the existing language ideologies in Ukraine," Tovares argues, "YouTube commenters' voices help create a foundation for grassroots ideological and political mobilization that privileges complexity over homogeneity." This is an example of Ukrainian society (and a grassroots movement) revealing itself through language.

\subsection{The question of semiotics and digital inclusion}

The discourse on social media and inclusion is further discussed by Sage Graham in "A Wink and a Nod: The Role of Emojis in Forming Digital Communities," which is a prime example of the second move in sociolinguistics from mobility to complexity. This is a multifaceted examination of the role of emojis-a main, intricate, and everchanging feature of digital interaction-in managing gender bias and forming digital, ludic communities. Accordingly, this study is a quintessential demonstration of the exceptional wave of research featured in this volume that transcends simplistic, binary conceptualizations of semiotic resources (e.g. emoji as phatic and emotive communicative tools) and contextualizes them instead as multifaceted, interactive, and mitigative of the local and the global, creating immediate, gendered, and cultural inclusion in a relatively hostile digital platform facing women. In this way, the study contributes to debates on digital discourse and marginalization (in particular as apropos to women and gaming). Hitherto, these debates have argued for a direct link (Salter \& Blodgett 2017: 75); in contrast, this paper demonstrates how such inclusion is realized though an interplay between emojis and language. The findings paint a complex view of emojis as tools for forming, defining, and reinforcing global norms of communities, demonstrating, as a result, how society (with all its biases, norms of interaction, and community-building challenges) is revealed through the lens of emojis in interaction with language.

Jan Blommaert brings the volume to an end in an intriguing, thoughtprovoking epilogue wherein he discusses the papers in light of current discourses, his own ground-breaking research, and future directions of a new reimagined sociolinguistics. 


\section{Concluding remarks}

By situating itself at the interface of the sociolinguistics of globalization and new media, this special issue contributes to productive discourses on a new theorization of sociolinguistics more attuned to reality and contributes to an ongoing and increasing need for innovative sociolinguistic theorizing and methodologizing in the age of globalization and digitization of communication. A new direction for sociolinguistics necessitates, as Blommaert argues in the epilogue, a re-imagining of both our social world and the lenses through which it is experienced, with a focus on social action. This reimagination, I argue, further necessitates highlighting under-represented contexts and cultures, often utilizing interdisciplinary and multimodal work. This is especially true in contexts that lack access to voice and opportunities, as it is in such contexts that the intricacies of social realities are revealed and our research tools are tested. As online and offline realities are not only intertwined, but they feed into each other and lead at times to historical change (see Aarsand 2008; Al Zidjaly 2019a, Al Zidjaly 2019b), the new sociolinguistic reimagination (and the new wave of new media sociolinguistics) I further argue necessitates examining how online activities trickle into and transform social realities and vice versa, because what happens online is changing the very fabric of many societies. And it is imperative for sociolinguistics to capture these changes in infancy if it intends to remain relevant.

Acknowledgements: Special thanks to the contributors in this project who participated in both the conference I chaired in Oman and the special issue. I will forever be indebted to Jan Blommaert for his plenary speeches in Oman, for writing up the epilogue to this volume, and for challenging us to revisit sociolinguistic research and methods. I finally thank Ingrid Piller for the opportunity she presented us to publish in Multilingua.

\section{Note}

All the contributors in this special issue took part in the international conference I organized and chaired in Oman (with Jan Blommaert as Plenary Speaker): Third International Conference on Language, Linguistics, Literature and Translation: Connecting the Dots in a Glocalized World. The conference took place on November 3-5, 2016 and was hosted by the Department of English Language and Literature (College of Arts and Social Sciences) at Sultan Qaboos University, Muscat, Oman. 


\section{References}

Aarsand, P. Andre. 2008. Frame switches and identity performances: Alternating between online and offline. Text \& Talk 28(2). 147-165.

Al Zidjaly, Najma. 2006. Disability and anticipatory discourse: The interconnectedness of local and global aspects of talk. Communication \& Medicine 3(2). 101-112.

Al Zidjaly, Najma. 2009. Agency as an interactive achievement. Language in Society 38. 177-200.

Al Zidjaly, Najma. 2010. Intertextuality and constructing Islamic identities online. In Rotimi Taiwo (ed.), Handbook of research on discourse behavior and digital communication: Language structures and social interaction, 191-204. New York: IGI Global.

Al Zidjaly, Najma. 2012. What has happened to Arabs? Identity and face management online. Multilingua 31. 413-439.

Al Zidjaly, Najma. 2014a. WhatsApp Omani teachers? Social media and the question of social change. Multimodal Communication 6(1). 15-45.

Al Zidjaly, Najma. 2014b. Geosemiotics: Discourses in place. In Sigrid Norris \& Carmen Daniela Maier (eds.), The reader in multimodality, 63-76. Berlin: de Gruyter.

Al Zidjaly, Najma. 2015. Disability, discourse and technology: Agency and inclusion in (Inter) action. London: Palgrave Macmillan.

Al Zidjaly, Najma. 2017. Memes as reasonably hostile laments: A discourse analysis of political dissent in Oman. Discourse \& Society 28(6). 573-594.

Al Zidjaly, Najma. 2018. Introductory notes to the panel on approaches to social media and activism (organized by Najma Al Zidjaly). GURT 2018: Georgetown University Round Table, Approaches to Discourse. March 9-11, 2018.

Al Zidjaly, Najma. 2019a. Digital activism as nexus analysis: A sociolinguistic example from Arabic Twitter. Tilburg Papers in Culture Studies, paper 221.

Al Zidjaly, Najma. 2019b. Embedded repair as activism on Arabic Twitter. In Cynthia Gordon (ed.), Approaches to discourse. Washington DC: Georgetown University Press.

Al Zidjaly, Najma \& Cynthia Gordon. 2012. Mobile phones as cultural tools: An Arabian example. Intercultural Management Quarterly 13(2). 14-17.

Androutsopoulos, Jannis. 2006. Introduction: Sociolinguistics and computer-mediated communication. Journal of Sociolinguistics 10(4). 419-438.

Androutsopoulos, Jannis. 2008. Potentials and limitations of discourse-centred online ethnography. Language@ Internet 5. 9.

Androutsopoulos, Jannis. 2013. Localizing the global on the participatory web. In Nikolas Coupland (ed.), The handbook of language and globalization, 203-231. Sussex: Wiley-Blackwell.

Appadurai, Arjun. 1996. Modernity at large: Cultural dimensions of globalization. Minneapolis: University of Minnesota Press.

Bakhtin, Mikhail. 1981. The dialogic imagination. Austin, TX: University of Texas Press.

Baron, S. Naomi. 2008. Always on: Language in an online and mobile world. Oxford: Oxford University Press.

Barton, David \& Mary Hamilton. 2005. Local literacies: Reading and writing in one community. London: Routledge.

Barton, David \& Carmen Lee. 2013. Language online: Investigating digital texts and practices. London: Routledge.

Baym, K. Nancy. 1995. The performance of humor in computer-mediated communication. Journal of Computer-Mediated Communication 1(2). http://onlinelibrary.wiley.com/ 
Baym, K. Nancy. 2015. Personal connections in the digital age: Digital media and society series. London: Polity.

Bell, Allan. 1984. Language style as audience design. Language in Society 13(2). 145-204.

Bell, Allan. 2016. Succeeding waves: Seeking sociolinguistic theory for the twenty-first century. In Nikolas Coupland (ed.), Sociolinguistics: Theoretical debates, 391-416. Cambridge: Cambridge University Press.

Blommaert, Jan. 2003. Commentary: A sociolinguistics of globalization. Journal of Sociolinguistics 7(4). 607-623.

Blommaert, Jan. 2005. Discourse: A critical introduction. Cambridge: Cambridge University Press.

Blommaert, Jan. 2010. The sociolinguistics of globalization. Cambridge: Cambridge University Press.

Blommaert, Jan. 2011. Supervernaculars and their dialects. Working Papers in Language and Literacies. Paper 81, 1-14.

Blommaert, Jan. 2015a. Chronotopes, scale and complexity in the study of language in society. Annual Review of Anthropology 44. 105-116.

Blommaert, Jan. 2015b. Chronotopic identities. Tilburg papers in Culture Studies, paper 144. https://www.tilburguniversity.edu/upload/83e91218-34c2-4cdd-9fe3-b5a587c690e7_ TPCS_144_Blommaert.pdf

Blommaert, Jan. 2016. From mobility to complexity in sociolinguistic theory and method. In Nikolas Coupland (ed.), Sociolinguistics: Theoretical debates, 242-259. Cambridge: Cambridge University Press.

Blommaert, Jan. 2017a. Durkheim and the Internet: On sociolinguistics and the sociological imagination. Tilburg Papers in Culture Studies, paper 173. https://www.tilburguniversity. edu/research/institutes-and-research-groups/babylon/tpcs/item-paper-173-tpcs.htm

Blommaert, Jan. 2017b. Ludic membership and orthopractic mobilization: On slacktivism and all that. Tilburg papers in Culture Studies, paper 193. https://www.tilburguniversity.edu/ upload/6cfbdfee-2f05-40c6-9617-d6930a811edf_TPCS_193_Blommaert.pdf

Blommaert, Jan. 2018a. Durkheim and the Internet: Sociolinguistics and the sociological imagination. London: Bloomsbury.

Blommaert, Jan. 2018b. Dialogues with ethnography. Notes on classics and how I read them. Bristol: Multilingual Matters.

Blommaert, Jan. 2018c. Are chronotopes helpful? Working Papers in Urban Language \& Literacies, paper 243.

Blommaert, Jan. 2018d. Context and its complications. Tilburg Papers in Culture Studies, paper 208.

Blommaert, Jan. 2018e. Formatting online actions:\#Justsaying on Twitter. Tilburg Papers in Culture Studies, paper 209.

Blommaert, Jan \& Anna De Fina. 2015. Chronotopic identities: On the timespace organization of who we are. Tilburg Papers in Culture Studies, paper 153. https://www.tilburguniversity. edu/upload/ba249987-6ece-44d2-b96b-3fc329713d59_TPCS_153_Blommaert-DeFina.pdf

Blommaert, Jan \& Ben Rampton. 2011. Language and superdiversity. Diversities 13(2). 1-22.

Blommaert, Jan \& Piia Varis. 2015. Enoughness, accent and light communities: Essays on contemporary identities. Tilburg Papers in Culture Studies, paper 139. https://www.tilburguniversity. edu/upload/5c7b6e63-e661-4147-a1e9-ca881ca41664_TPCS_139_Blommaert-Varis.pdf

Bou-Franch, Patricia \& Pilar Garcés-Conejos Blitvich (eds.). 2018. Analyzing digital discourse: New insights and future directions. London: Palgrave Macmillan. 
Bucholtz, Mary \& Kira Hall. 2005. Identity and interaction: A sociocultural linguistic approach. Discourse Studies 7(4-5). 585-614.

Castells, Manuel. 1996. The rise of the network society. London: Blackwell.

Cicourel, Aaron. 1964. Method and measurement in sociology. The social organization of juvenile justice. New York: Free Press.

Coupland, Nikolas. 1998. What is sociolinguistic theory? Journal of Sociolinguistics 2(1). 110-117.

Coupland, Nikolas. 2003. Introduction: Sociolinguistics and globalization. Journal of Sociolinguistics 7(4). 465-472.

Coupland, Nikolas. 2010. The authentic speaker and the speech community. In Carmen Llamas \& Dominic Watts (eds.), Language and identities, 99-112. Edinburgh: Edinburgh University Press.

Coupland, Nikolas. 2013. The handbook of language and globalization. Malden, MA: WileyBlackwell.

Coupland, Nikolas (ed.). 2016. Sociolinguistics: Theoretical debates. Cambridge: Cambridge University Press.

Crystal, David. 2011. Internet linguistics: A student guide. London: Routledge.

Danesi, Marcel. 2015. Language, society, and new media. London: Routledge.

De Fina, Anna, Deborah Schiffrin \& Michael Bamberg (eds.). 2006. Discourse and identity. Cambridge: Cambridge University Press.

De Fina, Anna, Didem İkizoğlu \& Jeremy Wegner (eds.). 2017. Diversity and super-diversity. Washington, DC: Georgetown University Press.

Du Bois, John. 2007. The stance triangle. In Robert Englebretson (ed.), Stancetaking in discourse: Subjectivity, evaluation, interaction, 139-182. Amsterdam: John Benjamins.

Duranti, Alessandro \& Charles Goodwin. 1992. Rethinking context: Language as an interactive phenomenon. Cambridge: Cambridge University Press.

Erickson, Frederick. 2004. Talk and social theory. London: Polity Press.

Gee, James P. 2005. Semiotic social spaces and affinity spaces: From the age of mythology to Today's schools. In David Barton \& Karen Tusting (eds.), Beyond communities of practice: Language, power and social context, 214-232. Cambridge: Cambridge University Press.

Gee, James P. 2014. Unified discourse analysis: Language, reality, virtual worlds and video games. London: Routledge.

Gee, James P. \& Elisabeth Hayes. 2011. Language and learning in the digital age. London: Routledge.

Georgakopoulou, Alexandra. 2006. Postscript: Computer-mediated communication in sociolinguistics. Journal of Sociolinguistics 10(4). 548-557.

Georgakopoulou, Alexandra. 2007. Small stories, interaction and identities. Amsterdam: John Benjamins.

Georgakopoulou, Alexandra \& Tereza Spilioti (eds.). 2016. The Routledge handbook on language and digital communication. London: Routledge.

Goffman, Erving. 1959. The presentation of self in everyday life. New York: Anchor Books.

Goffman, Erving. 1971. Relations in public: Microstudies of the public order. New York: Basic Books.

Gordon, Cynthia. 2015. “I would suggest you tell this $\wedge \wedge \wedge$ to your doctor”: Online narrative problem-solving regarding face-to-face doctor-patient interaction about body weight. In Franziska Gygax \& Miriam A. Locher (eds.), Narrative matters in medical contexts across disciplines, 117-140. Amsterdam: John Benjamins.

Graham, Sage L. 2007. Disagreeing to agree: Conflict, (im)politeness and identity in a computermediated community. Journal of Pragmatics 39. 742-759. 
Graham, Sage L. 2018. Ethical and methodological challenges in researching digital discourse. Unpublished conference paper. Gurt 2018: Approaches to Discourse. March 9-11, 2018. Washington DC.

Gumperz, John J. 1982. Discourse strategies. Cambridge: Cambridge University Press. Heller, Monica. 2007. Bilingualism: A social approach. London: Palgrave Macmillan.

Herring, Susan C. 1999. Interactional coherence in CMC. Journal of Computer-Mediated Communication 4(4). jcmc.indiana.edu/vol4/issue4/herring.html.

Herring, Susan C. 2004. Computer-mediated discourse analysis: An approach to researching online behavior. In Sasha Barab, Rob Kling \& James H. Gray (eds.), Designing for virtual communities in the service of learning, 338-376. New York: Cambridge University Press.

Herring, Susan C. 2013a. Discourse in Web 2.0: Familiar, reconfigured, and emergent. In Deborah Tannen \& Anna Marie Tester (eds.), Discourse 2.0: Language and new media, 1-25. Washington, DC: Georgetown University Press.

Herring, Susan C. 2013b. Relevance in computer-mediated conversation. In Susan Herring, Dieter Stein \& Tuija Virtanen (eds.), Handbook of pragmatics of computer-mediated communication, 245-268. Berlin: de Gruyter.

Herring, Susan C. \& Jannis Androutsopoulos. 2018. Computer-mediated discourse 2.0. In Deborah Tannen, Heidi Hamilton \& Deborah Schiffrin (eds.), The handbook of discourse analysis, 2nd, 127-151. Malden, MA: John Wiley \& Sons.

Hymes, Dell. 1996. Ethnography, linguistics, narrative inequality: Toward an understanding of voice. London: Taylor \& Francis.

Inda, Jonathan X. \& Renato Rosaldo. 2008. Tracking global flows. In Jonathan X. Inda \& Renato Rosaldo (eds.), The anthropology of globalization, 3-46. Oxford: Blackwell Publishing.

Jones, Rodney H. 2009. Dancing, skating and sex: Action and text in the digital age. Journal of Applied Linguistics 6(3). 283-302.

KhosraviNik, Majid. 2016. Social media critical discourse studies (SM-CDS)". In John Flowerdew \& John E. Richardson (eds.), The Routledge handbook of critical discourse studies, 582-596. London: Routledge.

Koutsogiannis, Dimitris \& Bessie Mitsiopoulou. 2007. Greeklish and greekness: Trends and discourses of "glocalness". In Brenda Danet \& Susan C. Herring (eds.), The multilingual internet: Language, culture and communication online. Cambridge: Cambridge University Press.

Kramsch, Claire \& Elizabeth Boner. 2013. Shadows of discourse: Intercultural communication in global contexts. In Nikolas Coupland (ed.), The handbook of language and globalization, 495-519. Malden, MA: Wiley-Blackwell.

Kytölä, Samu. 2016. Translocality. In Alexandra Georgakopoulou \& Tereza Spilioti (eds.), The Routledge handbook of language and digital communication, 371-387. London: Routledge.

Lee, Carmen. 2017. Multilingualism online. London: Routledge.

Lemke, Jay L. 2000. Across the scales of time: Artifacts, activities, and meanings in ecosocial systems. Mind, Culture and Activity 7(4). 273-290.

Locher, Miriam A., Andreas H. Jucker \& Manuel Berger. 2015. Negotiation of space in second life newbie interaction. Journal of Pragmatics 9. 34-45. https://doi.org/10.1016/j. dcm.2015.06.002.

Locher, Miriam A. \& Richard J. Watts. 2005. Politeness theory and relational work. Journal of Politeness Research 1(1). 9-33. 
Meredith, Joanne \& Elizabeth Stokoe. 2014. Repair: Comparing Facebook "chat" with spoken interaction. Discourse \& Communication 8(2). 181-207.

Morozov, Evgeny. 2011. The net delusion: The dark side of internet freedom. New York, NY: Public Affairs.

Norris, Sigrid. 2011. Identity in interaction: Introducing multimodal interaction analysis. Berlin: de Gruyter.

Ochs, Elinor. 1996. Linguistic resources for socializing humanity. In John Gumperz \& Stephen Levinson (eds.), Rethinking linguistic relativity, 407-437. Cambridge: Cambridge University Press.

Page, Ruth. 2010. Re-examining narrativitiy: Small stories in status updates. Text \& Talk 30(4). 423-444.

Park, Joseph Sung-Yul \& Adrienne Lo. 2012. Transnational South Korea as a site for a sociolinguistics of globalization: Markets, timescales, neoliberalism. Journal of Sociolinguistics 16(2). 147-164.

Pennycook, Alastair. 2007. Language, localization, and the real: Hip-hop and the global spread of authenticity. Journal of Language, Identity, and Education 6(2). 101-115.

Pennycook, Alastair. 2018. Semiotic assemblages: The pros and cons of trying to cover everything. Oral presentation as part of the Georgetown University Linguistics Department Speaker Series Event. Washington DC, USA. 5, October, 2018.

Piller, Ingrid. 2011. Intercultural communication: A critical introduction. Edinburgh: Edinburgh University Press.

Piller, Ingrid. 2016. Linguistic diversity and social justice: An introduction to applied sociolinguistics. Oxford: Oxford University Press.

Rampton, Ben. 1998. Speech community. In Jef Verschueren, Jan Ola Ostman, Jan Blommaert \& Chris Bulcaen (eds.), Handbook of pragmatics, 1-30. Amsterdam: John Benjamins.

Rampton, Ben. 1999. 'Deutsch' in inner London and the animation of an instructed foreign language. Journal of Sociolinguistics 3. 480-504.

Rampton, Ben. 2001. Critique in interaction. Critique of Anthropology 21. 83-107.

Rampton, Ben. 2006. Language in late modernity: Interactions in an urban school. Cambridge: Cambridge University Press.

Rheingold, Howard. 1993. The virtual community: Homesteading on the electronic frontier. From the World Wide Web. Reading, MA: Addison-Wesley. http://www.rheingold.com/vc/book/ (Retrieved December 19, 2017).

Rubdy, Rani \& Lubna Alsagoff. 2014. The global-local interface and hybridity. London: Palgrave Macmillan.

Rymes, Betsy \& Andrea R. Leone. 2014. Citizen sociolinguistics: A new media methodology for understanding language and social life. Working Papers in Educational Linguistics (WPEL) 29(2). Fall 2014. https://repository.upenn.edu/cgi/viewcontent.cgi? article $=1262 \&$ context $=$ wpel

Salter, Anastasia \& Bridget Blodgett. 2017. Toxic Greek masculinity in media: Sexism, trolling and identity policing. London, Palgrave Macmillan.

Schegloff, Emanuel A. 2007. Sequence organization in interaction. Cambridge: Cambridge University Press.

Schegloff, Emanuel A., Gail Jefferson \& Harvey Sacks. 1977. The preference for self-correction in the organization of repair in conversation. Language 53(2). 361-382.

Schiffrin, Deborah. 2000. Mother/daughter discourse in a Holocaust oral history: "Because then you admit that you're guilty." Narrative Inquiry 10(1). 1-44. 
Scollon, Ron. 2001. Mediated discourse: The nexus of practice. London: Routledge.

Scollon, Ron \& Suzie W. Scollon, 2004. Nexus analysis: Discourse and the emerging internet. London: Routledge.

Scollon, Ron \& LeVine Phillip (eds.). 2004. Discourse and technology: Multimodal discourse analysis. Washington DC: Georgetown University Press.

Seargeant, Philip \& Caroline Tagg. 2014. The language of social media: Identity and community on the internet. London: Palgrave Macmillan.

Silverstein, Michael. 1976. Shifters, verbal categories, and cultural description. In Keith Basso \& Henry Selby (eds.), Meaning in anthropology, 122-137. Albuquerque, NM: School of American Research.

Tannen, Deborah. 2001. Power maneuvers or connection maneuvers? Ventriloquization in family interaction. In Deborah Tannen \& James E. Alatis (eds.), Linguistics, language, and the real world: Discourse and beyond, 50-62. Washington DC: Georgetown University Press.

Thurlow, Crispin \& Kristine Mroczek (eds.). 2011. Digital discourse: Language in the new media. Oxford: Oxford University Press.

van Leeuwen, Theo. 2004. Ten reasons why linguists should pay attention to visual communication. In Ron Scollon \& Philip LeVine (eds.), Discourse and technology: Multimodal discourse analysis, 7-19. Washington DC: Georgetown University Press.

van Leeuwen, Theo \& Usama Suleiman. 2013. Globalizing the local: The case of an Egyptian superhero comic. In Coupland Nikolas (ed.), The handbook of language and globalization, 232-254. Malden, MA: Wiley-Blackwell.

Vasquez, Camilla. 2014. The discourse of online consumer reviews. Indiana: Bloomsbury Publishing.

Vertovec, Steven. 2007. Super-diversity and its implications. Ethnic and Racial Studies 30(6). 1024-1054.

Watson, Nick \& Alan Roulstone (eds.). 2014. The Routledge handbook of disability studies. London: Routledge.

Zappavigna, Michele. 2011. Ambient Affiliation: A linguistic perspective on Twitter. New Media \& Society 13(5). 788-806.

Zappavigna, Michele. 2012. Discourse of Twitter and social media: How we use language to create affiliation on the web. London: Continuum. 